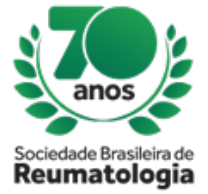

\title{
PERITONEAL AND PLEURAL TUBERCULOSIS SECONDARY TO ANTI-TNF THERAPY - CASE REPORT
}

Ana Gabriela Cardoso Ferraz (Hospital das Clínicas da UFG, GOIÂNIA, GO, Brasil), Gabriela Cardoso Barreto (Hospital Estadual Dr. Alberto Rassi (Hospital Geral de Goiânia), Goiânia, GO, Brasil), Érika Fernanda Faria (Hospital Estadual Dr. Alberto Rassi (Hospital Geral de Goiânia), Goiânia, GO, Brasil), Antônio Carlos Ximenes (Hospital Estadual Dr. Alberto Rassi (Hospital Geral de Goiânia), Goiânia, GO, Brasil), Fábia Mara Gonçalves Prates de Oliveira (Hospital Estadual Dr. Alberto Rassi (Hospital Geral de Goiânia), Goiânia, GO, Brasil)

\section{BACKGROUND}

The discovery of drugs that block the action of tumor necrosis factor, the called anti-TNF alpha, revolutionized the treatment of many inflammatory diseases; however, they have potentially serious side effects. One of them is the reactivation of latent tuberculosis, which in the presence of an immunosuppressive condition commonly presents as extrapulmonary forms. The authors present a case of peritoneal and pleural tuberculosis secondary to therapy with an immunobiological anti-TNF alpha (Adalimumab).

\section{CASE REPORT}

A 40-year-old female patient with Ankylosing Spondylitis started hospital follow-up in 2013. For four years, she was treated for AS with different drugs: nonsteroidal anti-inflammatory drugs, analgesics, glucocorticoids and sulfasalazine. There was no significant clinical improvement and, in February 2017, Adalimumab was initiated. In June 2018, the patient started myalgia, arthralgia, headache and nausea, accompanied by fever, chills and profuse sweating (predominantly nocturnal). A few days later, she presented diffuse abdominal pain, ascites and respiratory discomfort. Computed tomography of the abdomen showed reduced liver size; ascites of large volume; prominent lymph nodes in the hepatic wire and portocava space. Ascitic fluid analysis showed exudate, with a predominance of lymphocytes and positive ADA. Chest X-ray without changes. Videolaparoscopy revealed peritoneal thickening, with diffuse white-yellow lesions and fibroaderences. The histopathological analysis of these lesions showed caseous granulomas and the BAAR survey was positive. The hypothesis of peritoneal tuberculosis was confirmed and treatment started - RIPE scheme (Rifampicin, Isoniazid, Pyrazinamide and Etambutol). Two months later, the patient was readmitted into the hospital with dry cough, dyspnea, pleuritic pain and fever. Chest $x$-ray showed extensive pleural effusion on the right. Diagnostic thoracentesis: exudative pleural fluid, with predominance of lymphomononuclear cells and positive ADA; cytological analysis showed numerous reactive mesothelial cells; presence of lymphocytes, neutrophils and foamy macrophages; BAAR, fungal and oncology cytology researches were negatives. The findings pointed to pleural tuberculosis; the Infectology team oriented maintenance of and treatment was maintained with RIPE scheme. Currently, the patient is finishing the treatment for tuberculosis and remains without immunobiological drug.

\section{CONCLUSION}

Immunobiological therapies revolutionized the treatment of inflammatory diseases. However, the burden of these drugs are potentially serious side effects, including opportunistic infections. The reactivation of tuberculosis during the use of an anti-TNF- $\alpha$ drug is an example of this and this case reinforces the importance of constant monitoring of the adverse events of these medications. 